\title{
A Study on the "Flexibility" of Information Systems (Part 2): How can We Make Them Flexible?
}

\author{
Masaru Furukawa ${ }^{1}$ \\ ${ }^{1}$ Faculty of Economics, University of Toyama, Japan \\ Correspondence: Masaru Furukawa, Faculty of Economics, University of Toyama, Japan. E-mail: \\ frukawa@eco.u-toyama.ac.jp
}

Received: June 25, 2013

Accepted: August 16, 2013

Online Published: September 18, 2013

doi:10.5539/ijbm.v8n19p73

URL: http://dx.doi.org/10.5539/ijbm.v8n19p73

\begin{abstract}
This study analyzes the problems faced by information systems (IS) managers and elucidates that failure of their IS division to fully meet the needs of their corporate end-users causes these problems. IT evolution has been reviewed with a view to identify a solution for these issues. Studies have revealed that increased coverage of IS led to co-ordination difficulties among concerned parties and excessive workload for an IS division. On the basis of this finding, we analyzed the needs for IS architectural renovation and to structure the IS architecture into one with greater built-inflexibility, such that IS engineers can make prompt functional modifications and end-users can easily acquire proficiency in using the modified functions.

In this paper, we address our second question of how IS can be made flexible. We begin by citing the concept of "penalty of change" to define the relationship between the flexibility and utility of IS modifications in Part 1. Then, we discuss the need for IS architectural renovation and its role in reducing the complexity of IS functions, thereby enhancing IS flexibility. Next, we define the relevant "external" and "internal" flexibility factors underlying IS flexibility and analyze their interrelationship. Building on this groundwork, we conclude by proposing an appropriate procedure. We implement this procedure to construct a flexibility-oriented medium-term development plan, comprising the optimal combination of IS architectural renovation and a series of IS modification projects.
\end{abstract}

Keywords: IS flexibility, penalty of change, IS development, IS architecture, capacity requirements planning

\section{Introduction}

Despite or rather because of the remarkably rapid strides that management information systems have made in their coverage from within corporate borders to supply chain management, their development and renovation have often failed to be in satisfactory sync with the dynamic strategic needs of their corporate users.

These user organizations strive to realize competitive advantages through sustained management agility and adaptivity to dizzying changes in their business environment. However, the expanded coverage of information systems has led to difficult coordination among the people concerned and to an excessive workload that burdens corporate IS divisions with both modification and maintenance of their current systems. Often, these IS divisions do not have sufficient technological capability in promptly delivering IS modifications that fit dizzily changing corporate strategic needs, and corporate end users themselves do not have enough technological literacy to effectively utilize the modified service.

This state of affairs is attributable to these computer-based systems, whose structure is not sufficiently simple and lacks flexibility in enabling both IS engineers and end users to easily deal with IS modifications. Therefore, regarding our first question-Why do information systems need to be flexible?-Part 1 argued for the pressing need of IS architectural renovation. That is, the need is to structure IS architecture into one that eliminates unwieldy complexity and has greater built-in flexibility, such that IS engineers can more easily make prompt functional modifications and end users can easily acquire proficiency in using these modified functions.

This paper addresses our second and more practical question: "How can we make information systems flexible?" More specifically, we first define the nature of IS architecture renovation to contribute to the enhancement of IS flexibility and analyze the "external" and "internal" flexibility factors underpinning IS flexibility. We then present our notion of an appropriate manner in which we should construct a 
flexibility-oriented medium-term development plan, comprising IS architectural renovation and a series of IS modification projects. Also, we adopt our concept of penalty of charge (POC) to provide an idealized numerical model of the flexibility behavior over time that involves the implementation of the plan.

\section{Previous Studies and Research Question}

Information Economics (Parker \& Benson, 1988) identified six types of IS value: investment, management information, competition, strategy support, competitive edge, and information technology infrastructure (ITI). It defined the value of ITI that supports the generation of other values. Duncan (1995) discussed the concepts of IT resource management, including technological architecture, planning alignment, and human resource skills, all of which are linked to definitions of ITI, and introduced the concept that flexibility is either developed or thwarted in deferent circumstances. Byrd and Turner (2000) explored the predictive validity of the instruments with possible antecedent and consequent variables. The scheme to evaluate flexibility as a degree of freedom in the assumed operation methods seems analogous to the evaluation of freedom in tool exchanges or mechanical operations as flexibility in flexible manufacturing systems (FMSs).

Insufficient flexibility can limit the success of an IS by preventing its use in certain circumstances and necessitating exception handling. Also, insufficient flexibility can reduce the overall lifetime of a system. However, excessive flexibility can limit IS success by limiting usability (Silver, 1991) and increasing complexity (Economist, 2004), thus requiring larger investments, longer implementation time, and higher subsequent operating and maintenance costs (Soh et al., 2003).

Today, IS managers face various choices regarding IS flexibility, ranging from turnkey systems with little room for subsequent changes to IS architectures with numerous options for future change (Rum baugh et al., 1991). Currently, various IT innovations are available that appear effective, yet require significant upfront investments.

The introduction to Gebauer \& Schober (2006) indicated "that practical evidence as reported to the authors by a number of IS managers and consultants in Europe and in the United States suggests that in lieu of clear guidelines regarding the economic management of MIS flexibility, MIS investment decisions may be based on factors such as short-term political considerations, risk aversion, tight budgets, and 'me-too' desires at the expense of MIS flexibility that may only pay out in the longer term".

IS research has addressed IS effects on organizational flexibility and competitive advantage (Palanisamy \& Sushil, 2003) and the typically contradictory IS effects on organizational flexibility and efficiency (Allen \& Boynton, 1991; Robey \& Boudreau, 1999).However, thus far, the economics of IS flexibility has received comparatively little attention. Nevertheless, research in system requirement engineering, which refers to the process of formulating, documenting, and maintaining software requirements, has long highlighted that nonsystematic and unstructured analyses of IS requirements can lead to suboptimal results (Robinson \& Pawlowski, 1999).

On the basis of this awareness, Gebauer and Schober (2006) defined IS flexibility as efficiency in the use and provision (or change) of the system function for supporting operativity not as a tool but as a business process, and proposed a scheme for evaluating a given business process in terms of cost efficiency.

In a study connecting corporate management and ITI, Fink and Neumann (2009) used a resource-based view of the firm and a dynamic capabilities perspective to account for the competitive effects of flexibility. They also reported that the range of managerial ITI capabilities, which were positively affected by all areas of IT personnel knowledge and skills, was responsible for the competitive effects of ITI-enabled flexibility.

Furukawa (2000) expanded "the probabilistic approach based on prediction proposed as a flexibility evaluation method of FMS" (Chryssolouris \& Lee, 1992) and applied it to ITI evaluation as a method of analyzing ITI value in Information Economics. The proposal on IS flexibility evaluation is based on the concept that the demand for change in a business process needs provision or change in IS function, which requires cost and time as $P O C$. Moreover, this research proposed a plan to prepare ITI equipped with sufficient flexibility to absorb future changes in demands, thus acquiring intercorporate competitive advantages. That is, this research 1) is premised on the importance of ITI in intercorporate competition (Fink \& Neumann, 2009); 2) sets up cost efficiency to support business processes as a problem in the provision (or change) of an IS function (Gebauer \& Schober, 2006); and 3) is challenging with respect to developing ITI as a tool equipped with necessary the flexibility (Byrd \& Turner, 2000).

On the basis of these research findings, Furukawa (2000) proposed a practical method for IS managers that allows for sufficient IS flexibility when faced with various choices regarding this flexibility (i.e., various option selections with respect to IS flexibility). In addition to proposing a theory of IS flexibility, a more general goal 
was to establish the relevance of IS value evaluation for successful IS management and to link business value to IS value through IS flexibility. Therefore, we inherit Furukawa's (2000) objective and clarify the countermeasures of the problem that an IS manager faces. Thus, this paper addresses the research question "How can we make information systems flexible?"

First, we confirm the finding so four previous study on "Why do information systems need to be flexible?"

\section{IS Flexibility and Change Demands}

To support the effort of its end-user organization in finding strategic solutions to pressing problems, an IS should be equipped with effective functions capable of data extraction and analysis with maximal ease. Moreover, because these solutions imperatively demand prompt functional modifications that involve the processing of relevant information, an IS should be structured such that it is relieved of the unwieldy complexity that impedes its prompt disposal. Thus far, we referred to the property of general simplicity built into an IS as IS flexibility, which we believe should and can be enhanced through proper renovation of its architecture.

In this and the subsequent section, we more precisely define the nature of IS flexibility and clarify the necessity to predict demands for future changes to an IS, such as those subsequently discussed, and the connotation of renovating an IS architecture such that it is maximally flexible in dealing with these anticipated demands.

\subsection{Definition of IS Flexibility in Terms of POC}

When an IS function (F) is effectively utilized (U), an IS yields the utility of contributing to the performance of the end-user organization. We consider this utility as a reward (IS reward) that the organization receives by appropriately utilizing its IS. We then express $I S$ reward as follows:

$$
\text { IS reward }=f(F, U)
$$

Therefore, IS reward is a mathematical function $(f)$ of the combination of the functions $(F)$ that the IS provides and the organization's ability to utilize the functions $(U)$.

Irrespective of their sizes, most present-day organizations utilize their IS for business management. That no organization can hope for effective business management without the aid of an IS is no exaggeration. Therefore, an organization's performance can be defined as a product of business interactions, largely accomplished from the utilization of the functions and the quality provided by its IS as well as the cost and time required to develop and maintain them.

Drawing on Parker and Benson's six types of IS value and the value of ITI supported to generate the others, we postulate IS contribution to organizational performance as the "value of the IS" (IS Value); the IS Value is represented in the following form:

$$
\text { IS value }=\frac{I S \text { reward }}{g(C, T)}=\frac{f(F, U)}{\text { Penalt of Change }}
$$

where the denominator $g(C, T)$ is a function of the cost $(C)$ and time $(T)$ required to develop and maintain the organization's IS and can be regarded as the penalty that every IS manager pay for changing the organization's IS. Hereafter, we refer to this penalty as $P O C$, as did Chryssolouris \& Lee (1992), who used the term in the context of mechanical engineering. The IS Value newly yielded increases in proportion as the value of the numerator $f(F, U)$ increases and/or as the value of the denominator $P O C$ decreases. The alleviation of IS managers' problems, as addressed in Part 1, requires there duction of the denominator value. As has been clarified to date, this requirement can be satisfied by the enhancement of IS flexibility. For the present purpose, if we eliminate the numerator, we can posit IS flexibility in the following form:

$$
\text { IS flexibility }=\frac{1}{\text { Penalty of Change }}=\frac{1}{P O C}
$$

Note that equation (3) represents the relationship between IS flexibility and POC, i.e., the higher the IS flexibility, the smaller the $P O C$ and, conversely, the lower the IS flexibility, the larger the POC. The preferred situation is a larger reward and smaller penalty (POC). Enhancement of IS flexibility alleviates the POC payable by IS managers such as ours and their other related problems. The equation indicates that $P O C$ is usable as an index of IS flexibility; i.e., IS flexibility - the in-built ease with which to modify an IS - can be quantitatively evaluated in terms of $P O C$.

\subsection{Probabilistic Definition of POC and IS Flexibility}

Chryssolouris (1996) defined "change" as the probabilistic event of a transition from a certain state to another. 
Since this definition is helpful for the present study's objective, we adopt the idea and express the probabilistic calculation of potential $P O C$ payable for possible future changes in the following form:

$$
P O C=\sum_{i=1}^{n} P O C\left(X_{i}\right) \operatorname{Pr}\left(X_{i}\right)
$$

where $X_{i}$ represents the state after change $i, P O C\left(X_{i}\right)$ represents the penalty of change $i$ (a function of cost and time), and $\operatorname{Pr}\left(X_{i}\right)$ represents the occurrence probability of change $i$.

$\operatorname{Pr}\left(X_{i}\right)$, a variable in the determination of $P O C$, indicates the probability of the possible occurrence of a future demand for change. $P O C\left(X_{i}\right)$ indicates the potential penalty to be incurred to meet the demand. To this effect, we paraphrase our definition of IS flexibility into the following question:

"How flexible an IS should we acquire at the time of its proactive architectural renovation if we are to meet possible future demands for its functional modifications as and when they occur?"

The underlying assumption of this paper, as is postulated in equation (3), is that $P O C$ is a critical variable affecting IS flexibility. Therefore, to answer the aforementioned question in concrete terms, we seek answers to the next question:

"How can we, at the time of its proactive architectural renovation, properly incorporate into our IS such flexibility factors as will serve to minimize the potential POC to be incurred by the disposal of possible future demands for its functional modifications?"

\subsection{IS Change Demands and the Need for Enhanced IS Performance}

To acquire IS value, a corporation deals with environmental change demands. Typically, the demands for changes to a corporate IS are for the provision of newly required business applications along with user interfaces to be implemented on an external design. These demands are attributable to the need to respond to new developments that are both internal and external to an organization (Parker \&Benson, 1988):

a) Organization external: new government policies, e.g., implementation of environment accounting and change in consumption tax rate.

Note that demands for IS functional modifications in this regard typically require disposal by the appointed time. Delay in due-date delivery of these demands only aggravates the business disadvantage that the concerned organization may be sustaining against its competitors.

b) Organization internal: new management strategies or standard operating procedures (SOPs) aimed, e.g., at higher return on investment (ROI), enhanced management information, and acquisition of a competitive edge.

The implementation of IS changes in response to these demands requires management resources (e.g., throughput in terms of cost, time, and computer storage capacity and person-hours to be spent by experienced technical staff). However, that these required resources are adequately provided for immediate use when change projects are to be undertaken is rarely the case; often, a corporate IS division cannot process all change demands in due time. Such delays in IS modification lead to delays in the execution of management strategies, those in the renovation of business processes, and other similar delays, and consequently, to the corporation's loss of a golden opportunity to gain intercorporate competitive superiority. To break out of this vicious circle, the IS division must acquire the expertise to predict future demands for change and renovate the IS architecture such that it is equipped with sufficient anticipatory preparedness to manage with minimal $P O C$ when faced with such change demands. Doing so calls for adaptability of innovative technologies such as the exchange of ITI components; minor improvements (kaizen) to make current business applications more fail-safe; and the implementation of a database management system (DBMS), computer-aided system engineering (CASE), innovative telecommunication technology, and/or cloud computing. Also, although IT innovations such as component-based and service-oriented software architectures (Bieberstein et al., 2006), web services (Whiting, 2003), autonomous computing concepts (Horn, 2001), and mobile applications (Siau et al., 2001) promise greater flexibility than the mainframe, client/server, and non-mobile systems they are meant to replace, they require significant upfront investments.

\section{Renovation of IS Architecture}

By "equipment of an IS with anticipatory preparedness," we imply the renovation of IS architecture for that purpose. In general, IS changes are prone to be accompanied by change risks (e.g., system unusable or system failure). This problem has spawned various technologies and methodologies for its pre-emption ("risk evasion strategies") (Table 1). Ad hoc attention to these change risks adds extra $P O C$ to that for IS modifications. Thus, 
to minimize this doubly onerous modification $P O C$, these risks should be pre-empted by properly incorporating risk-evasion strategies into the renovation of the IS architecture (DeLone \& McLean, 1992).

These evasion strategies are expected to provide more than ad hoc pre-emption of individual change risks. As McFarlan (1981) pointed out, many project failures are attributable to the architectural complexity of the modified system as well as the scale of the system project and the inadequacy of engineers' technological experiences. The structural complexity of IS applications is such that their modification produces many problems that predominantly can often be resolved by highly skilled engineers. The challenge is to eradicate the root cause of this difficulty. The nature of an IS architectural renovation should be such that it eradicates this complexity, thereby enhancing internal flexibility factors, that are assumed to fundamentally facilitate IS functional modifications in addition to practically pre-empting their vulnerability to risk.

Table 1. IS risks incurred by system changes, risk evasion strategies, and other causes

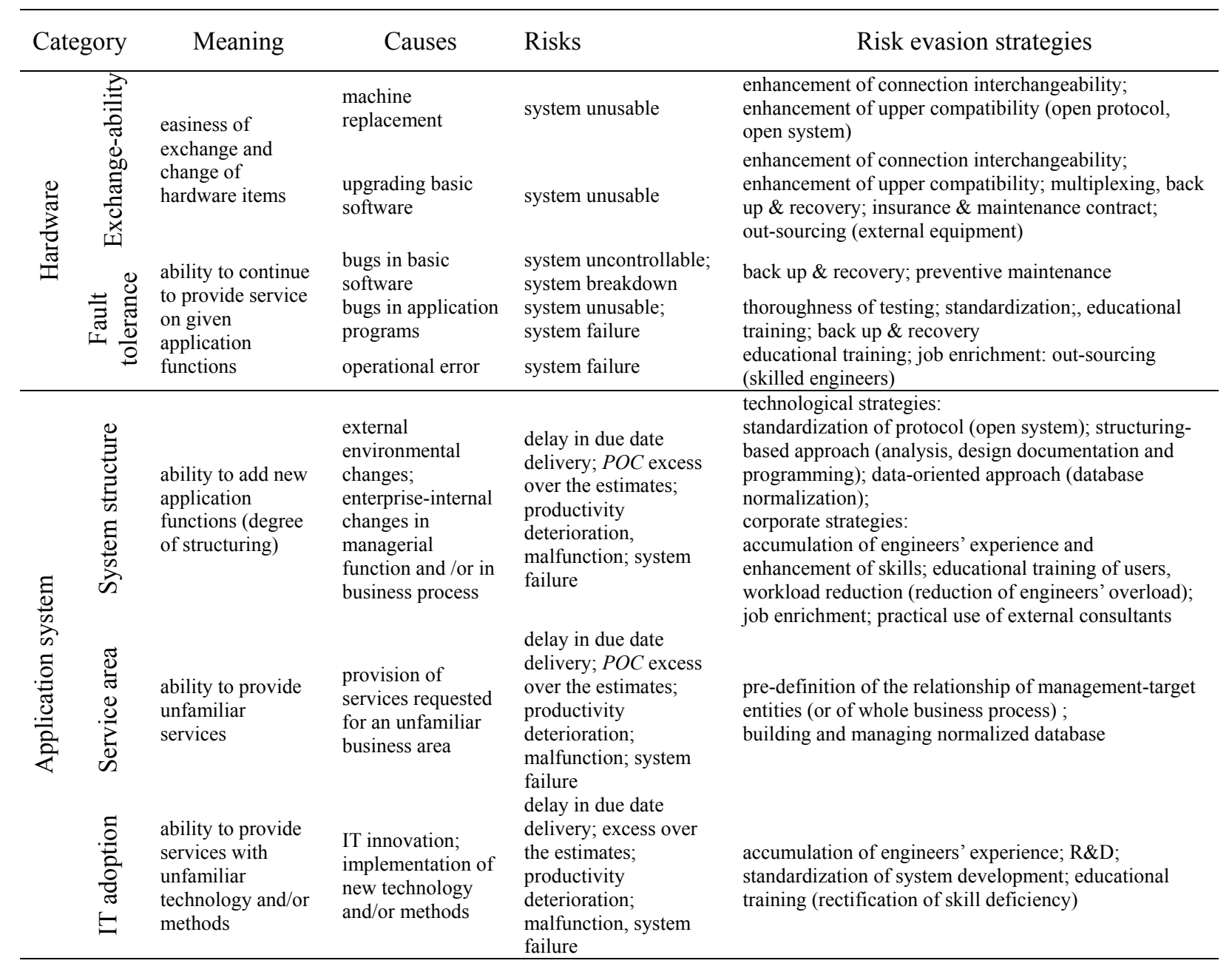

Note: Adapted from Furukawa (2001).

However, in this sense, IS architectural renovation inevitably incurs a significant $P O C$ of its own. This is often a major hindrance to its unhesitating implementation and accounts for the reluctance of many IS divisions to propose renovations to their IS architecture. However, despite this reluctance, the $P O C$ that architectural renovation incurs can be more than compensated for by the benefit that it generates through the reduction of the potential risk vulnerability of future IS modifications and, consequently, by avoiding extra $P O C$ payable for system faults liable to accompany them. Therefore, the only way to overcome their dilemma is to develop a good enough methodology to evaluate this benefit and the consequent higher ROI that it would fetch relative to the renovation $P O C$ - one reliable and convincing enough to obtain the required resources from management.

Equation (5) shows how, despite $P O C_{\mathrm{R}}$, proper renovation of IS architecture yields utility $\left(U T L_{\mathrm{R}}\right)$ by reducing 
the $P O C_{\mathrm{M}}$, which potential future IS modifications otherwise incur because it fundamentally facilitates these modifications through the enhancement of internal flexibility factors and the lowering of their risk vulnerability.

$$
P O C_{P O S T}=P O C_{M}+\left(P O C_{R}-U T L_{R}\right)
$$

where $P O C_{\mathrm{M}}$ represents $P O C$ normally payable for future IS modifications, $P O C_{\mathrm{R}}$ represents $P O C$ paid for an architectural renovation, $U T L_{\mathrm{R}}$ represents the utility of an infrastructural renovation, and $P O C_{\mathrm{POST}}$ (literally post-renovation $P O C$ ) represents the net $P O C$ payable for all IS changes, including architectural renovation.

Thus, proper renovation of IS architecture can be expected to ensure greater ease and efficiency in IS modification. Therefore, a corporate IS division should consider vigorously promoting the renovation of IS architecture from a long-term perspective as an important mission.

\section{Structure of IS Flexibility Factors}

Given the aforementioned change demands, our task is to elucidate the flexibility factors that an IS secures and efficiently deals with such demands. For a preliminary exposition of these factors, we bear in mind expertise in production planning and scheduling and, for a more technical and detailed analysis of the structure of $I S$ flexibility, we draw on expertise in flexible manufacturing systems (Browne, 1984).

To swiftly manage business-related change demands, a corporate IS division needs to implement capacity requirements planning (CRP), a method generally used in manufacturing (Ceryan \& Koren, 2009). A division uses CRP on a short-term basis to manage the working sequence to cover the required $P O C_{M}$ (i.e., capacity requirements) using its current capacity. To provide for predictable change demands, a division may be required to enhance its current capacity and/or reduce anticipated future capacity requirements (i.e., $P O C_{M}$ ) on a medium- to long-term basis. The IS architectural renovation needs to be of a nature that simultaneously satisfies both these needs. CRP also needs to consider the workload (i.e., $P O C_{R}$ ) of this renovation.

However, considering the following caveats about personnel management is necessary.

Assigning more engineers to a project that frequently falls behind schedule has the adverse effect of complicating communication among the staff and, consequently, further delaying the project (Brooks, 1974).

IS development depends more on engineers' experience and skill than on tools (K. Laudon \& L. Laudon, 2000). However, inevitable reliance on particular competent engineers frequently and disproportionately overburdens them and eventually hinders the smooth progress of development (Goldratt, 1997).

\subsection{External IS Flexibility Factors}

External IS flexibility factors involve the efficiency of an IS in the disposal of the end user's demands when obliged to meet them with current capacity. As noted, typical change demands are to modify business applications and are necessitated by changes in the business environment. These demands need to be swiftly met by providing IS "products" in the form of modified applications. To deliver the products by the due date and cover capacity requirements using current capacity, efforts must be made to control the "volume" of $P O C$ (person-months) by choosing appropriate production methods, such as a system development approaches (e.g., business process and data modeling and prototyping), project management (e.g., traditional waterfall, critical chain (Goldratt, 1997), lean (Plenert, 2011), extreme (Wysocki, 2009)), and the recent agile methodologies (e.g., extreme programming [Beck and Andres, 2004] and Scrum [Hulet, 2004]).To optimally utilize current capacity, additional effort must be made to maneuver the "working sequence." Also, when the $P O C$ required for functional modification $\left(P O C_{M}\right)$ is projected to exceed current capacity, IS architectural renovation must be implemented for its pre-emptive reduction; however, this adds a $P O C$ of its own (i.e., $P O C_{R}$ ) to the capacity requirements (i.e., the required volume of $P O C$ ). Product, volume, and working sequence are the external factors underlying the degree of freedom for managing this type of difficult endeavor. We now define these external factors in greater detail.

\subsubsection{Product}

This factor refers to the degree of freedom in the selection of methods for functional modification and in the diversification of IS products in the form of modified functions. These methods may include the following, among others: combination of existing components in a new way or in addition to new ones; reconstruction (i.e., scrap and build) of a current application function by drawing on new technology and methodology; and outsourcing a part or all of the components. A complexity reduction in the system through architectural renovation reduces the difficulties related to product delivery. Different methods selected require different amounts of $P O C_{\mathrm{M}}$ for product development. 


\subsubsection{Volume}

This factor refers to the degree of freedom in modulating the volume of $P O C_{\mathrm{M}}$ required to develop demanded products (i.e., the capacity requirements). When the volume is projected to exceed an IS division's current capacity, it needs to be reduced by some means. Flexible modulation of the volume depends on the methods employed in the development of particular types of products demanded. By contrast, despite the $P O C_{\mathrm{R}}$ to be added to capacity requirements, IS architectural renovation - if implemented in anticipation of predictable change demands - will enhance the capacity of an IS.

\subsubsection{Working Sequence}

This factor refers to the degree of freedom that allows the jumping of job queues when the prioritization of change demands is needed to ensure disposal of every one of them by the due date. This flexibility presupposes the availability of alternative means in terms of the development environment and the engineer staff required to deal with high-priority urgent jobs. In this sense, readjustment of the working sequence simultaneously meets the CRP's key objective of leveling the demand-incurred workload in a given period below the uppermost limit of a corporate IS division's current capacity. This factor is constrained by the IS architecture structuring, and is subsequently discussed in relation to the internal flexibility factor of "system structure."

\subsection{IS Architectural Renovation and Internal IS Flexibility Factors}

Internal IS flexibility factors refer to the IS architecture's internal properties that underpin the efficacy of the external factors discussed, which we assume can be enhanced through IS architectural renovation. When an IS is evaluated for its quantitative absorbency of change demands, an important factor is the stable availability of the ITI ("exchangeability" and "fault tolerance"). When business applications are to be modified, the difficulty of the work depends on how they are structured (system structure). Although an IS comprises multiple subsystems, its internal flexibility is affected not so much by how individual subsystems have been constructed, but by how its IS architecture has been structurally renovated (system structure). When subsystems are to be constructed, the $P O C$ payable for their development and the quality of the finished products significantly depend on the degree of experience and knowledge, which the engineers involved in their development have on the target domain ("service area") of the subsystems.

These dependence relationships are related to the internal factors (the previous parenthesized expressions that are subsequently defined) that affect the efficiency of the disposal of change demands.

First, we examine the internal factors that affect the renovation of ITI. An IS consists of hardware such as computers with basic installed software, storage, communication equipment, and application systems software consisting of programs and data for business use. Typical hardware renovation is implemented when the need exists for 1) a speedy exchange of items to supplement IS capacity and to ensure complete disposal of all change demands and 2) a renewal to stabilize the availability of the entire hardware platform and to reduce the probability of system breakdowns. The first need involves the internal exchangeability factor and the second need involves fault tolerance.

\subsubsection{Exchangeability}

This factor refers to the flexibility with which hardware items are exchanged or hardware capacity is enhanced (e.g., exchange of or increase in computers, including vendor change; storage enlargement; and change in communication equipment). Flexible exchange or renovation of hardware items or hardware capacity enable the provision of the demanded business applications through a greater variety of products. The flexible combination of hardware items makes readjusting working sequences easier. That is, higher exchangeability enhances the external factors of product and working sequence.

\subsubsection{Fault Tolerance}

This factor refers to the flexibility with which to maintain system availability, even in the face of a partial or total system breakdown, and to swiftly recover the system. This tolerance to system faults presupposes the advance provision of functional fallbacks that are indispensable to surviving these breakdowns. Enhanced system availability improves the external volume factor that, in turn, enhances the external working sequence factor.

In contrast, modification of business applications varies with respect to the level of difficulty depending on whether such modifications involve the internal system structure factor, i.e., the structural amenability of the current system to modification, another internal service area factor, i.e., familiarity with the target domain of a business application to be modified, or yet another external internal factor of IT adoption, i.e., the technological 
proficiency of an IS division that affects the adaptability of technology that is new to its staff.

\subsubsection{System Structure}

This factor refers to the structurally derived ease with which newly demanded application functions are constructed by combining components of existing business applications on ITI. This factor presupposes that, to prevent functional modification from affecting any other component but the relevant ones, these existing applications are structurally comprise building blocks (i.e., subsystems and program modules) of normalized functional units that are independent of each other. It also presupposes the independence of data from programs and the structuring of data in the form of a database. Because the elimination of structural complexity allows doe easier execution of functional modification through mere combinations of relevant application components, it will simplify the process of providing products that satisfy newly demanded functional requirements. Therefore, this elimination of complexity will serve to reduce the volume of programs to be modified or newly developed. In turn, enhancement of the external volume factor will enhance the flexibility of the working sequence. In effect, the internal system structure factor will contribute to the enhancement of all of the external factors: product, volume, and working sequence.

\subsubsection{Service Area}

This factor, involving the serviceability of an IS, refers to the flexibility with which to provide services in unfamiliar or new areas. IS implementation or modification is particularly prone to risk when it involves unfamiliar service areas. To say nothing of the fortunate familiarity with the entities that the new service area shares with the previous one, the predefinition of the entity relationship within the entire business processes of the new area will help compensate for the lack of experience and knowledge of its business processes(Figure 1).Thus, designing and developing business functions for that area will be much easier, in turn enhancing the flexibility with which to provide products that satisfy the demanded functional requirements. The consequent labor reduction for system design and development will enhance the external volume factor, in turn enhancing the external working sequence factor.
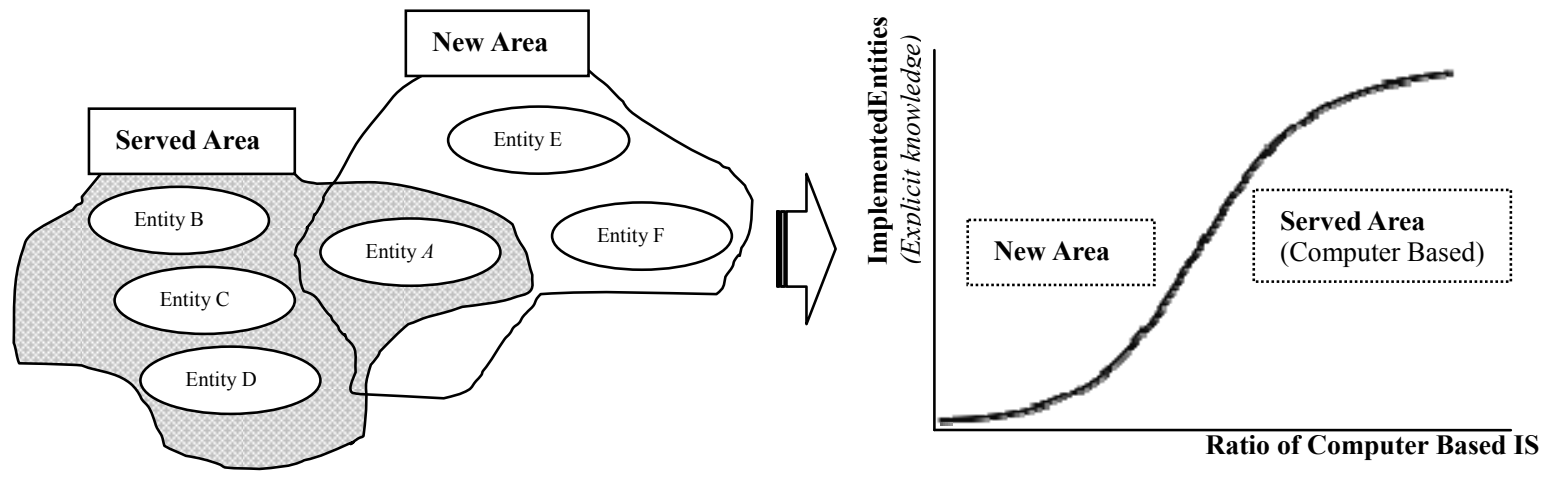

Figure 1. Entity shared by served area and new area

Note: Entities A, B, C, D are implemented into database. Entity E and F are not implemented.

\subsubsection{IT Adoption}

This factor, involving the technological capabilities of an organization and the innovative efforts of its IS division, refers to the flexibility with which to provide services using unfamiliar or new technology and development methods. Similar to the internal service area factor, the lack of technological experience generates risks. However, risks of this kind are dissolved through the accumulation of experience and proficiency in the use of new technology (Alter\& Ginzberg, 1978; McFarlan, 1981). Therefore, the improvement in technological proficiency over time will inversely proportionally reduce the $P O C$ payable for system development (Figure 2). The enhancement in proficiency from new technology will enhance the facility with which to realize products that satisfy the demanded functional requirements. The reduction in person-months for system design attributable to enhanced technological proficiency will positively affect the external volume factor, in turn enhancing the external working sequence factor. 


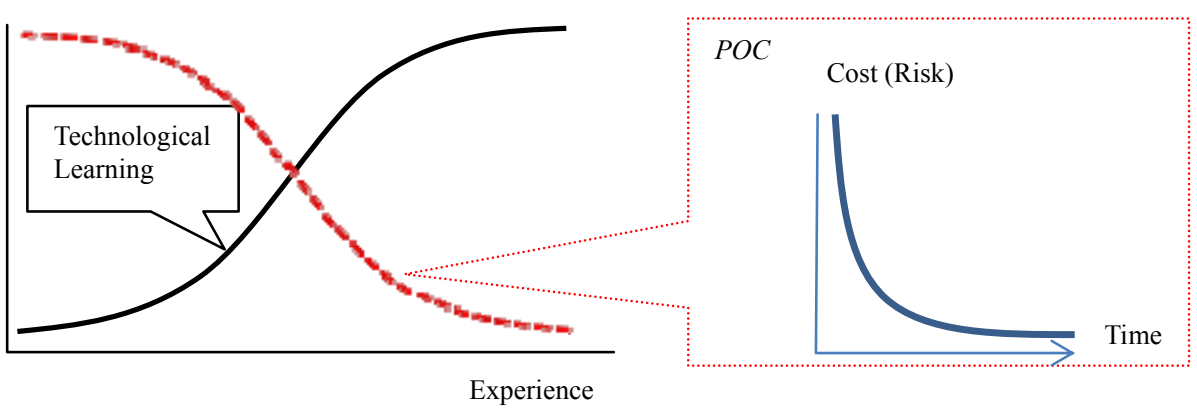

Figure 2. Technological learning and $P O C$

\section{Evaluation of IS Flexibility}

\subsection{Guideline for IS Flexibility Evaluation}

We provided definitions of the external and internal factors of IS flexibility and clarified the relationships between them. To evaluate IS flexibility in terms of $P O C$, defining in greater detail the components of equation (5) in relation to cost and time is necessary (i.e., $P O C_{M}, P O C_{R}$, and $U T L_{R}$ ). Doing so requires the identification of the nature of risk-prone changes, change risks, and strategies for their evasion. Table 1 provides a list of these factors. Table 2 shows the indexes for their evaluation for each internal flexibility factor. The following exposition will provide guidelines to evaluate each internal flexibility factor.

Table 2. Internal flexibility factors and indexes for their evaluation

\begin{tabular}{|c|c|c|c|c|c|c|}
\hline \multirow{2}{*}{\multicolumn{2}{|c|}{ Category }} & \multirow{2}{*}{ Meaning } & \multicolumn{4}{|c|}{ Indexes for Evaluation } \\
\hline & & & Viewpoint & Cost & Time & Utility \\
\hline \multirow{2}{*}{ 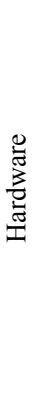 } & 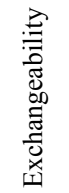 & $\begin{array}{l}\text { easiness of } \\
\text { exchange and } \\
\text { change of } \\
\text { hardware }\end{array}$ & $\begin{array}{l}\text { enhancement of connection } \\
\text { interchangeability; enhancement of } \\
\text { upper compatibility (open protocol, } \\
\text { open system) }\end{array}$ & $\begin{array}{l}\text { human resources } \\
\text { (person month) }\end{array}$ & $\begin{array}{l}\text { time distance } \\
\text { (exchange speed) }\end{array}$ & $\begin{array}{l}\text { reduction of } \\
\text { exchange time; } \\
\text { reduction of } \\
\text { cost }\end{array}$ \\
\hline & 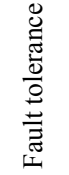 & $\begin{array}{l}\text { ability to continue } \\
\text { to provide } \\
\text { services on given } \\
\text { application } \\
\text { functions }\end{array}$ & availability & $\begin{array}{l}\text { opportunity loss; } \\
\text { recovery cost }\end{array}$ & MTBT, MTTR & $\begin{array}{l}\text { reduction of } \\
\text { opportunity } \\
\text { loss and } \\
\text { recovery cost }\end{array}$ \\
\hline \multirow{4}{*}{ 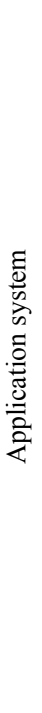 } & \multirow{2}{*}{ 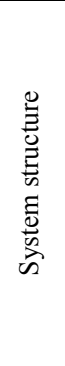 } & \multirow[b]{2}{*}{$\begin{array}{l}\text { ability to add new } \\
\text { application } \\
\text { functions (degree } \\
\text { of structuring) }\end{array}$} & structuring of systems and programs & $\begin{array}{l}\text { cost for change } \\
\text { demand disposal; } \\
\text { cost for } \\
\text { structuring }\end{array}$ & $\begin{array}{l}\text { time for change } \\
\text { demand disposal ; } \\
\text { time for } \\
\text { structuring }\end{array}$ & $\begin{array}{l}\text { reduction of } \\
P O C \text { for } \\
\text { design }\end{array}$ \\
\hline & & & $\begin{array}{l}\text { quality of database (number of access } \\
\text { paths from application program to data, } \\
\text { number of programs and data requiring } \\
\text { change, ratio of management-target } \\
\text { entities included in database); } \\
\text { tendency of backlog volume on the time } \\
\text { axis }\end{array}$ & $\begin{array}{l}\text { cost for change } \\
\text { demand disposal; } \\
\text { cost for database } \\
\text { development }\end{array}$ & $\begin{array}{l}\text { time for change } \\
\text { demand disposal; } \\
\text { time for database } \\
\text { development }\end{array}$ & $\begin{array}{l}\text { reduction of } \\
P O C \text { for } \\
\text { design }\end{array}$ \\
\hline & 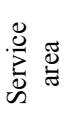 & $\begin{array}{l}\text { ability to provide } \\
\text { unfamiliar } \\
\text { services }\end{array}$ & $\begin{array}{l}\text { ratio of BPs and management-target } \\
\text { entities provided with a service }\end{array}$ & $\begin{array}{l}\text { cost for change } \\
\text { demand } \\
\text { disposal; ; cost } \\
\text { for new service }\end{array}$ & $\begin{array}{l}\text { cost for change } \\
\text { demand; } \\
\text { cost for new } \\
\text { service }\end{array}$ & $\begin{array}{l}\text { reduction of } \\
P O C \text { for } \\
\text { design }\end{array}$ \\
\hline & 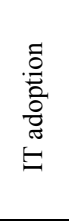 & $\begin{array}{l}\text { ability to provide } \\
\text { services with } \\
\text { unfamiliar } \\
\text { technology and/or } \\
\text { methods }\end{array}$ & $\begin{array}{l}\text { technological continuity and degree of } \\
\text { experience }\end{array}$ & $\begin{array}{l}\text { cost for change } \\
\text { demand disposal; } \\
\text { cost for expertise } \\
\text { enhancement } \\
\text { depending on } \\
\text { proficiency } \\
\text { levels }\end{array}$ & $\begin{array}{l}\text { time for change } \\
\text { demand disposal; } \\
\text { time for expertise } \\
\text { enhancement } \\
\text { depending on } \\
\text { proficiency levels }\end{array}$ & $\begin{array}{l}\text { reduction of } \\
P O C \text { by } \\
\text { learning }\end{array}$ \\
\hline
\end{tabular}

Note: Adapted from Furukawa (2001). 


\subsection{Evaluation Guidelines Involving Hardware}

\subsubsection{Exchangeability}

To evaluate this aspect of flexibility, we must estimate the $P O C$ to be incurred by future exchanges and by the implementation of architectural renovation as well as its utility in terms of the reduction in $P O C$ for potential future exchanges. In other words, we need to predict time and frequency at which we need to exchange hardware components comprising the existing IS, list exchange methods, and estimate the $P O C$ for executing each exchange method in terms of the require dperson-days (cost and time). In this regard, risk evasion strategies include standardization of protocol and maintenance contracts. A risk reduction from applying these strategies in combination can be regarded as their utility and needs to be estimated as such.

\subsubsection{Fault Tolerance}

The nature of this factor requires that its evaluation focus on system availability. Generally, a combination of mean time between failures (MTBF) and mean time to repair (MTTR) is used as an evaluation index. As groundwork for the evaluation, we list the causes of system breakdowns, monitor their frequency of occurrence for each type, and estimate the $P O C$ to be incurred by their future occurrence. The $P O C$ for the implementation of risk evasion strategies can be evaluated in terms of the required cost and time for a combination of IT implementations. The utility of risk evasion can be evaluated in terms of predictable reduction in the $P O C$ for opportunity loss and system recovery to be incurred from potential future system breakdowns.

\subsection{Evaluation Guidelines Involving Business Applications}

Modification of business applications means employment of various development methods to execute alterations of current IS components and the addition of new ones in appropriate combinations. In other words, to realize application functions that will meet end users' change demands, we can and must consider multiple-candidate system alternatives. To evaluate the relative merits of these alternatives, the potential $P O C$ for the development of each needs to be estimated, as does that for proactive implementation of architectural renovation and its utility. In these respects, the estimation of $P O C$ requires a comprehensive assessment of the effects that enhancement of the following internal flexibility factors can possibly exert on its reduction.

\subsubsection{System Structure}

The nature of this factor requires its evaluation to focus on how specific forms of structuring applied to application systems contribute to the ease of their modification or to the reduction of their predicted $P O C$. The $P O C$ for the implementation of evasion strategies needs to be estimated in relation to the specific forms of structuring administered to business applications, programs, and data. In the data structure evaluation, the fundamental indexes are the number of access paths from an application program to the data and the number of programs and data items that need to be changed. A suitable criterion for evaluation of an IS data structure is the ratio of entities incorporated into the database to all entities of management in the business process (BP) (i.e., whether the data are normalized and a data dictionary is provided). The utility of database incorporation can be estimated in terms of a reduction in the $P O C$ compared with the potential $P O C$ to be incurred when a DBMS is not properly utilized. Moreover, economic evaluation requires clarification on how a $P O C$ for system implementation and its utility differ depending on whether specific forms of structuring are applied to the system.

\subsubsection{Service Area}

Management entities within an enterprise seldom undergo any fundamental change, unless an exceptional change occurs in the industry type. Such a change indicates a transition in the business functional procedure involves no concomitant change in entity, and hardly affects the enterprise's data structures built on a data-oriented approach (Martin \& Leben, 1989). Therefore, in a comprehensive evaluation of anenterprise's existing IS, it would be reasonable to focus on the ratio of service-target entities to whole entities under the concerned management. As for a new service area, the focus of evaluation should be on the degree to which service-target entities in the new area include service targets in the familiar area. In the evaluation of $P O C$, with respect to this flexibility factor, we must estimate the $P O C$ for each system alternative as in the case of the factor of "system structure." Since entities for management are stable, system design will incur POC only once. Thus, since the design utility remains effective in the future system development, economic utility can be evaluated in terms of the reduction of $P O C$ (reduction of person-months for system design) due to the partial dispensability of labor for system design in the unfamiliar area. 


\subsubsection{IT Adoption}

The degree of connectedness between familiar technology and newly adopted technology significantly affects the time needed to learn new skills to use the latter. When new technology is adopted, inadequate proficiency in its use can lower productivity. Therefore, evaluation of a system alternative for this factor should focus on the potential growth in technological proficiency. In contrast, the assessment of the $P O C$ for a system alternative and to implement architectural renovation should consider the positive effect of the predictable growth of technological proficiency over time. Growth in technological proficiency will correspondingly decrease the $P O C$ that will have to be paid.

\subsection{Behavior of IS Flexibility (the Coston the Time Axis)}

As shown, IS architectural renovation is strategically intended to pre-empt change risks by eliminating the complexity of an IS, to which these risks are considered primarily attributable. Reduced IS complexity, as well as the resultant decrease in system failures, reduces the workload for system improvement and maintenance. These reductions make it easier for an IS to dispose of system modifications demanded and contribute to the agile response of the concerned organization to changes in the business environment.

Presumably, the usefulness of an IS manifests over time in its utilization process. Figure 3, based on Table 3, is a heuristic model of IS flexibility and illustrates the hypothetical behavior of IS flexibility on the time axis, assumed to be enhanced by a proactive IS architectural renovation in terms of its beneficial effects on functional modifications and on the resultant "Net Utility" of IS use. Note that the numerical values entered in all of the squares of the figure are abstract hypothetical units representing the costs or benefits of changes in the IS.

In this instance, the IS architecture renovation is proactively implemented in the first year with a view to enhancing the efficiency of future functional modifications. Despite its huge implementation cost, the renovation is assumed to start generating its utility from the next year in terms of the role that it will play in pre-empting change risks that are likely to accompany the system modifications and the cost reduction that their implementation will entail. Three modification projects $\left(\mathrm{IS}_{1}, \mathrm{IS}_{2}\right.$, and $\left.\mathrm{IS}_{3}\right)$ are planned for each of the three consecutive years after the architectural renovation. The cost for each of these projects is to be incurred in the fiscal year of their respective implementation, and the utility of each modification is assumed to be generated in the following years. Note that, to simplify exposition, cost and utility are hypothesized to be the same for all modifications.

Table 3. Net utility of IS plotted on the time axis

\begin{tabular}{|c|c|c|c|c|c|c|c|c|c|c|c|}
\hline \multirow{2}{*}{$\begin{array}{l}\text { Fiscal } \\
\text { Year }\end{array}$} & \multirow{2}{*}{$\begin{array}{l}\text { Cumulative } \\
\text { Net Utility }\end{array}$} & \multirow{2}{*}{$\begin{array}{l}\text { Gross Utility } \\
\text { of IS } \\
\text { Modification }\end{array}$} & \multicolumn{3}{|c|}{$\begin{array}{c}\text { Utility of IS } \\
\text { Modification }\end{array}$} & \multirow{2}{*}{$\begin{array}{c}\text { Gross Cost } \\
\text { of IS } \\
\text { Modification }\end{array}$} & \multicolumn{3}{|c|}{$\begin{array}{c}\text { Cost of IS } \\
\text { Modification }\end{array}$} & \multirow{2}{*}{$\begin{array}{c}\text { Utility of } \\
\text { Architectural } \\
\text { Renovation }\end{array}$} & \multirow{2}{*}{$\begin{array}{c}\text { Cost of } \\
\text { Architectural } \\
\text { Renovation }\end{array}$} \\
\hline & & & IS1 & IS2 & IS3 & & IS1 & IS2 & IS3 & & \\
\hline 1 & $-2,000$ & 0 & 0 & 0 & 0 & 2,000 & 1,000 & 0 & 0 & 0 & 1,000 \\
\hline 2 & $-1,550$ & 50 & 50 & 0 & 0 & 1,600 & 100 & 1,000 & 0 & 500 & 1,000 \\
\hline 3 & -400 & 150 & 100 & 50 & 0 & 550 & 50 & 100 & 1,000 & 600 & 0 \\
\hline 4 & 130 & 300 & 150 & 100 & 50 & 170 & 50 & 50 & 100 & 30 & 0 \\
\hline 5 & 430 & 550 & 300 & 150 & 100 & 120 & 50 & 50 & 50 & 30 & 0 \\
\hline 6 & 630 & 750 & 300 & 300 & 150 & 120 & 50 & 50 & 50 & 30 & 0 \\
\hline 7 & 780 & 900 & 300 & 300 & 300 & 120 & 50 & 50 & 50 & 30 & 0 \\
\hline 8 & 780 & 900 & 300 & 300 & 300 & 120 & 50 & 50 & 50 & 30 & 0 \\
\hline 9 & 780 & 900 & 300 & 300 & 300 & 120 & 50 & 50 & 50 & 30 & 0 \\
\hline 10 & 780 & 900 & 300 & 300 & 300 & 120 & 50 & 50 & 50 & 30 & 0 \\
\hline Total & 360 & 5,400 & 2,100 & 1,800 & 1500 & 5,040 & 1,500 & 1,450 & 1,400 & 1,310 & 2,000 \\
\hline
\end{tabular}




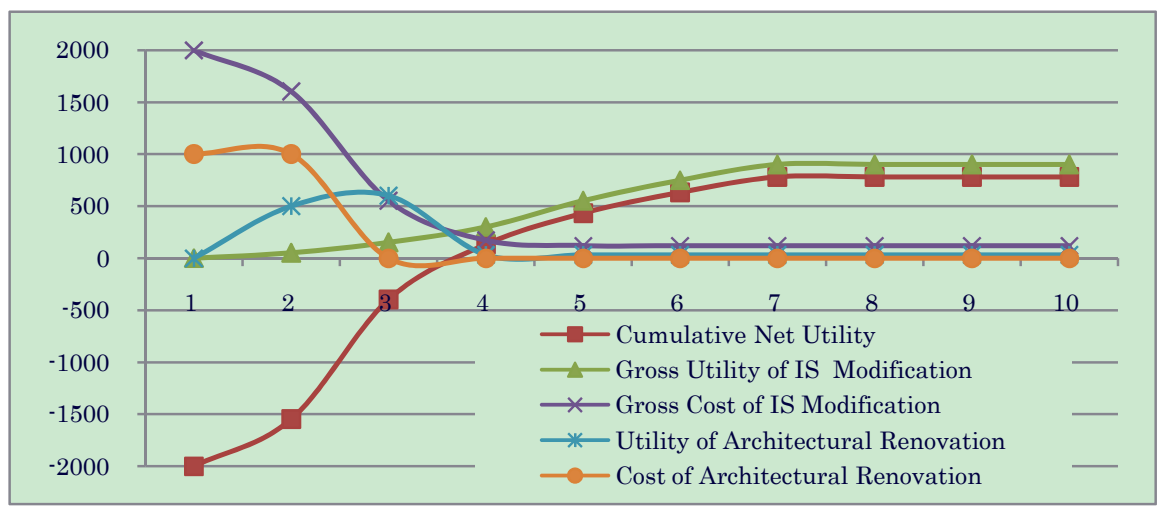

Figure 3. Net utility of IS plotted on the time axis

Figure 3 indicates that the effects of the IS architectural renovation manifest, albeit with a time lag, in the upward turn that Net Utility takes from negative to positive values. This turn represents proof that IS architectural renovation contributes to enhancing IS flexibility. Therefore, we can schematically represent the structure underlying the behavior of IS flexibility through the following equations on the basis of equation(5):

$$
\begin{gathered}
P O C_{\text {POST }}=\text { POC }_{M}+\left(\text { POC }_{R}-U T L_{R}\right) \\
\operatorname{Cost}_{\text {POST }}(t)=\text { Cost }_{M}(t)+\left(\operatorname{Cost}_{R}(t)-U T L_{R}(t)\right), \\
U T L_{N E T}(t)=U T L_{\text {POST }}(t)-\operatorname{Cost}_{\text {POST }}(t)
\end{gathered}
$$

where $\operatorname{Cost}_{\mathrm{M}}(t)$ represents the gross cost of a functional modification, $\operatorname{Cost}_{\mathrm{R}}(t)$ represents the cost of an IS architectural renovation, $U T L_{\mathrm{R}}(t)$ represents the utility of an IS architectural renovation, $\operatorname{Cost}_{\mathrm{POST}}(t)$ represents the net cost for all IS changes including the IS architectural renovation, $U T L_{\mathrm{POST}}(t)$ represents the utility of IS use, and $U T L_{\mathrm{NET}}(t)$ represents the net utility of IS use, each for a given fiscal year $(t)$.

However, despite the benefit of an architectural renovation, the "Cumulative Net Utility of IS Use" column reveals that cost and utility require considerable lead time to reach the breakeven point. The challenge for an IS division is to determine how best to reduce the lead time through an exhaustive evaluation of the relative merits of system alternatives and to proactively implement IS architectural renovation that matches the most appropriate alternatives.

\subsection{Procedure for IS Planning through Flexibility Evaluation}

We have been probing for a satisfactory answer, if any, to "How can we make an IS flexible?"We do so because this question is deemed to be one that no business organization can shirk if it is to make its management agile enough in a highly competitive environment. In the preceding paragraphs, we analyzed the structure underlying the role that IS architectural renovation is supposed to play in enhancing IS flexibility. Our next task is to map out the IS planning procedure in that IS flexibility is optimally incorporated into an IS.

Generally, the first step in strategic management is to set several medium-term business goals, followed by designing strategies to attain these goals. An IS needs to secure adequate flexibility in advance by proactively implementing architectural renovation and being sufficiently flexible to allow prompt and economical disposal of any functional modifications that these strategies demand. We propose that IS planning be executed through the following procedure.

\section{Step 1: Prediction of Future Demands}

In this step, we predict change demands likely to be made on an IS that originate from medium-term management strategies to address organization-external changes and to envisage functional modification projects to satisfy these demands. Figure 3 presumes the modification projects of $\mathrm{IS}_{1}, \mathrm{IS}_{2}$, and $\mathrm{IS}_{3}$.

\section{Step 2: Functional Modifications and External Flexibility Analysis}

In this step, we enumerate all possible candidate system alternatives for system modification projects envisaged in Step 1 and to assess IS flexibility (including POC in terms of management resources) required for these alternatives. Because we consider the immediate question of managing system modifications, we confine the consideration of the required IS flexibility to the external factors. The relevant questions relate to the external factors are as follows: 


\subsubsection{Product}

What system alternatives are applicable to the accomplishment of each envisaged modification project?

Possible system alternatives for $\mathrm{IS}_{1}$ might be 1) modification of the current IS, 2) development of a new system, or 3) customization of an application package.

What combinations of system alternatives need to be considered for a series of modification projects envisaged for the medium term?

A possible combination of system alternatives comprise 2) for $\left.\mathrm{IS}_{1}, 1\right)$ for $\mathrm{IS}_{2}$ and 3) for $\mathrm{IS}_{3}$.

\subsubsection{Volume}

What amounts of management resources will a combination of system alternatives require for their implementation and use?

The resources required for a combination of system alternatives need to be estimated to assess whether their implementation will be possible in light of the present condition of the current system and the relevant technology and methodologies available.

Table 4. Factors for $P O C$ calculation

\begin{tabular}{|c|c|c|c|c|c|c|c|c|c|c|c|}
\hline \multirow{3}{*}{$\begin{array}{l}\dot{0} \\
\frac{\pi}{0} \\
\dot{0} \\
\dot{n}\end{array}$} & \multicolumn{4}{|c|}{ Change Demand $k(l=3)$} & & & & \multirow{3}{*}{$\begin{array}{l}\text { Occurrence } \\
\text { Probability of } \\
\text { Change } X \\
\text { Pr(ip) }\end{array}$} & \multicolumn{3}{|c|}{ Evaluation for Mapping IS Plans } \\
\hline & \multirow{2}{*}{$\begin{array}{l}\infty \\
11 \\
2 \\
2\end{array}$} & \multicolumn{3}{|c|}{$\begin{array}{c}\text { Combination of } \\
\text { Alternatives }\left(A l_{j k p}\right)\end{array}$} & \multicolumn{3}{|c|}{$\begin{array}{l}\text { Set of Risk Evasion } \\
\text { Strategies } S t_{i p} i=n(p)\end{array}$} & & \multirow{2}{*}{$\begin{array}{c}\text { Required } \\
\text { Net Cost }= \\
P O C(c)^{I)}\end{array}$} & \multirow{2}{*}{$\begin{array}{c}\text { Required Net } \\
\quad \text { Time }= \\
P O C(t)^{l)}\end{array}$} & \multirow[t]{2}{*}{$\operatorname{Plan}_{\mathrm{pi}}$} \\
\hline & & $\begin{array}{c}k=1, \\
j=1,2\end{array}$ & $\begin{array}{c}k=2, \\
j=1,2\end{array}$ & $\begin{array}{c}k=3, j \\
=1,2\end{array}$ & & & & & & & \\
\hline 1 & & & & & & $S t_{11}$ & $\mathrm{ST}, \mathrm{TT}^{2)}$ & $\operatorname{Pr}_{11}$ & & & $\operatorname{Plan}_{11}$ \\
\hline 2 & & & & & $n$ & $S t_{21}$ & $\begin{array}{l}\text { ST, CD, } \\
\text { PC, ET }\end{array}$ & $\operatorname{Pr}_{21}$ & & & $\operatorname{Plan}_{12}$ \\
\hline 3 & 1 & $A l_{111}$ & $A l_{121}$ & $A l_{131}$ &. & $S t_{31}$ & ST, CD & $\operatorname{Pr}_{31}$ & & & $\operatorname{Plan}_{13}$ \\
\hline 4 & & & & & & $S t_{41}$ & $\begin{array}{c}\mathrm{CD}, \mathrm{PC}, \\
\mathrm{TT}\end{array}$ & $\operatorname{Pr}_{41}$ & & & $\operatorname{Plan}_{14}$ \\
\hline 5 & & & & & & $S t_{51}$ & ET, TT & $\operatorname{Pr}_{51}$ & & & $\operatorname{Plan}_{15}$ \\
\hline 6 & & & & & $\sim$ & $S t_{12}$ & ST, TT & $\operatorname{Pr}_{12}$ & & & $\operatorname{Plan}_{21}$ \\
\hline 7 & 2 & $A l_{112}$ & $A l_{122}$ & $A l_{232}$ & $\stackrel{\|}{\sim}$ & $S t_{22}$ & $\begin{array}{l}\text { ST, CD, } \\
\text { PC, ET }\end{array}$ & $\operatorname{Pr}_{22}$ & & & $\operatorname{Plan}_{22}$ \\
\hline 8 & & & & & & $S t_{13}$ & ST, TT & $\operatorname{Pr}_{13}$ & & & $\operatorname{Plan}_{31}$ \\
\hline 9 & 3 & $A l_{113}$ & $A l_{223}$ & $A l_{133}$ & $\stackrel{N}{\sim}$ & $S t_{23}$ & $\begin{array}{l}\text { ST, CD, } \\
\text { PC, ET }\end{array}$ & $\operatorname{Pr}_{23}$ & & & $\operatorname{Plan}_{32}$ \\
\hline 10 & & & & & & $S t_{14}$ & ST, TT & $\operatorname{Pr}_{14}$ & & & $\operatorname{Plan}_{41}$ \\
\hline 11 & 4 & $A l_{114}$ & $A l_{224}$ & $A l_{234}$ & $\stackrel{\pi}{I}$ & $S t_{24}$ & $\begin{array}{l}\text { ST, CD, } \\
\text { PC, ET }\end{array}$ & $\operatorname{Pr}_{24}$ & & & $\operatorname{Plan}_{42}$ \\
\hline 12 & & & & & & $S t_{34}$ & ST, CD & $\operatorname{Pr}_{34}$ & & & $\operatorname{Plan}_{43}$ \\
\hline 13 & & & & & & $S t_{15}$ & ST, TT & $\operatorname{Pr}_{15}$ & & & $\operatorname{Plan}_{51}$ \\
\hline 14 & 5 & $A l_{215}$ & $A l_{125}$ & $A l_{135}$ & $\stackrel{N}{\|}$ & $S t_{25}$ & $\begin{array}{l}\text { ST, CD, } \\
\text { PC, ET }\end{array}$ & $\operatorname{Pr}_{25}$ & & & $\operatorname{Plan}_{52}$ \\
\hline 15 & & & & & & $S t_{16}$ & ST, TT & $\operatorname{Pr}_{16}$ & & & $\operatorname{Plan}_{61}$ \\
\hline 16 & 6 & $A l_{216}$ & $A l_{126}$ & $A l_{236}$ & $\stackrel{\pi}{\|}$ & $S t_{26}$ & $\begin{array}{l}\text { ST, CD, } \\
\text { PC, ET }\end{array}$ & $\operatorname{Pr}_{26}$ & & & $\operatorname{Plan}_{62}$ \\
\hline 17 & & & & & & $S t_{17}$ & ST, TT & $\operatorname{Pr}_{17}$ & & & $\operatorname{Plan}_{71}$ \\
\hline 18 & 7 & $A l_{217}$ & $A l_{227}$ & $A l_{137}$ & $\stackrel{n}{n}$ & $S t_{27}$ & $\begin{array}{l}\text { ST, CD, } \\
\text { PC, ET }\end{array}$ & $\operatorname{Pr}_{27}$ & & & $\operatorname{Plan}_{72}$ \\
\hline 19 & & & & & & $S t_{37}$ & ST, CD & $\operatorname{Pr}_{37}$ & & & $\operatorname{Plan}_{73}$ \\
\hline 20 & & & & & & $S t_{18}$ & ST, TT & $\operatorname{Pr}_{18}$ & & & $\operatorname{Plan}_{81}$ \\
\hline 21 & 8 & $A l_{218}$ & $A l_{228}$ & $A l_{238}$ & $\stackrel{n}{\|}$ & $S t_{28}$ & $\begin{array}{l}\text { ST, CD, } \\
\text { PC, ET }\end{array}$ & $\mathrm{Pr}_{28}$ & & & $\operatorname{Plan}_{82}$ \\
\hline 22 & & & & & & $S t_{38}$ & ST, CD & $\operatorname{Pr}_{38}$ & & & $\operatorname{Plan}_{83}$ \\
\hline
\end{tabular}

Here, for simplicity we have used the sum of $P O C(c)$ and $P O C(t)$ values for the alternatives comprising each threesome combination. ST: Standardization, CD: CASE/DBMS, PC: Practical use of consultants, ET: Education / Training, TT: Thoroughness of testing. 


\subsubsection{Working Sequence}

Can the IS skillfully maneuver the working sequence (by jumping the job queue, if necessary) to make the best of the management resources currently available and unfailingly deliver on due-date completion of the modification projects?

We attempt to put the formulation of the enhancement of IS flexibility or the minimization of POC in more exact and probability theoretical terms. We refer to a change demand as $k(1 \leq k \leq l)$ [e.g., serve new area, change business process, etc.], a system alternative for $k$ as $j(1 \leq j \leq \mathrm{m}(k))$ [e.g., 2 (Table 4). Such as scrap and build, minimum modification, etc.], a combination of system alternatives for $k$ as $p(1 \leq p \leq q)$ [e.g., standardization, structuring, and/orarchitectural renovation via new technology, etc.], and the number of these combinations as $q[$ e.g., $q=\mathrm{n}(1) \times \mathrm{n}(2) \times \ldots \times \mathrm{n}(l)=2 \times 2 \times 2=8$ ] . Then, to process all $l[$ e.g., 3] change demands, we need to account for $q$ combinations of system alternatives.

Given the aforementioned notation, we might represent $P O C_{\mathrm{M}}(p)$, the penalty for a combination of system alternatives $(p)$, with the following equation in terms of $P O C_{\mathrm{M}}(\mathrm{kp})$ (the penalty for a system alternative) and $\operatorname{Pr}_{\mathrm{M}}(k p)$ (the subjective probability of its adaptability) [Furukawa \& Minami, 2013]:

$$
P O C_{M}(p)=\sum_{k=1}^{l} P O C_{M}(k p) \operatorname{Pr}_{M}(k p) \text {. }
$$

\section{Step 3: Architectural Renovation and Internal Flexibility Analysis}

As equation (5) shows, we can expect IS flexibility to be enhanced by appropriate IS architectural renovation. This step addresses the question of how to link optimal IS architectural renovation to an optimal combination of system alternatives. First, we predict for each of the combinations of system alternatives their likely concomitant change risks and their probability of occurrence. Next, we enumerate multiple sets of risk evasion strategies $(i$ $(1 \leq i \leq \mathrm{n}(p))$ to be adopted in anticipation of each of the combinations of system alternatives $(p(1 \leq p \leq q))$ and to estimate their utility $U t l_{\mathrm{R}}(i p)$ in reducing the risks that are likely to accompany system modifications, their own penalty $P O C_{\mathrm{R}}(i p)$, and the probability $\operatorname{Pr}_{\mathrm{R}}(i p)$ of the adaptability of each set.

As clarified, implementation of risk evasion strategies means giving concrete form to an architectural renovation. To enable an IS to efficiently provide application products in a series of modification projects, it is necessary to proactively bolster its system flexibility through optimal renovation of its architecture to enhance the structuredness of the IS, namely by preparing an optimal set of risk evasion strategies that match the predicted modifications. This process calls for the analysis of the relative merits of alternative sets of evasion strategies in terms of relevant internal flexibility factors, namely system structure, service area, and IT adoption.

Table 4 illustrates Plan $_{\mathrm{pi}}$, a total of 22 that each linka set of risk evasion strategies to a combination of system alternatives. Our ultimate aim is to determine how to select a combination of system alternatives that are bolstered by an appropriate set of risk evasion strategies that will optimally contribute to a reduction inthe $P O C$ to be incurred in IS implementation. Then, using equation (6) involving external flexibility, let equation (7) represent a combination of system alternatives that are proactively bolstered by a well-matched IS architectural renovation that will register a minimal net $P O C$ :

$$
P O C_{\min }=\min _{p=1}^{q}\left\{\min _{i=1}^{n(p)}\left(P O C_{M}(p)+\left(P O C_{R}(i p) \operatorname{Pr}_{R}(i p)-U t t_{R}(i p) \operatorname{Pr}_{R}(i p)\right)\right\} .\right.
$$

This idealized model of flexibility enhancement constructed in equation (7) provides us with a reference frame for identifying an optimal IS plan for the medium term to deal with all predictable change demands. The complex factors involved in decision making make seeking a practical algorithm for our model almost meaningless. In practice, therefore, there is nothing for it but to rely on a kind of experience-based subjective probability and to make our planning approximate as closely as possible to what our model suggests.

\section{Step 4: Decision Making on the Combinations of System Alternatives}

To conclude our evaluation procedure, we consider what an IS division actually must do if it is to identify an appropriate practical plan (i.e., Plan $_{\mathrm{pi}}$ ). As an example, we take an imaginary IS division that plans three system modifications $\left(\mathrm{S}_{1}-\mathrm{S}_{3}\right)$ during a ten-year period (Table 4 and Figure3). We assume that these modifications need to be processed by a staff of 20 engineers. The successful completion of each project by the due date requires an estimation of the person-months as well as an appropriate decision on the leader and the number of engineers to be assigned to them. Also, the efficient implementation of these projects needs to be preceded by renovation of IS architecture, which also requires the assignment of an appropriate number of engineers and its leader. As Figure3suggests, IS architectural renovation needs to be assessed for its potential utility in terms of the degree to 
which it serves to reduce the lead time on system modifications and how soon the net utility can balance out the total cost (we assume that renovation continues to generate its utility over time). Table 4 presupposes this type of simulation performed on 22 candidate plans in an attempt to optimize the POC balance sheet that involves all aspects of the IS implementation.

Because a key factor to be considered in this simulation is the "person-months" required (e.g., 10 person-months $=5$ persons $\times 2$ months $=2$ persons $\times 5$ months), we must exactly define the concept of person-month for our purpose. Apart from other cost factors, if "person" is substituted with "cost," this concept is re-definable in terms of "cost and time," which is exactly what we mean by our POC concept. Implementation of IS development depends on limited resources, including human resources such as engineers with different skills and experiences. In IS planning, as represented in Table 4, POC needs to be assessed in terms of cost and time, i.e., how many engineers to assign to each project in an appropriate manner and how much time to devote to it.

Figure 4 shows $P{ }^{2} n_{\mathrm{pi}}$ simplistically plotted on the coordinate axes of Required Net Cost $[P O C(c)]$ and Net Time $[P O C(t)]$ (Table 4). A comparison of the mapped plans with one another easily identifies Plan $_{42}$ as a plan with minimum $P O C$, namely with maximum flexibility.

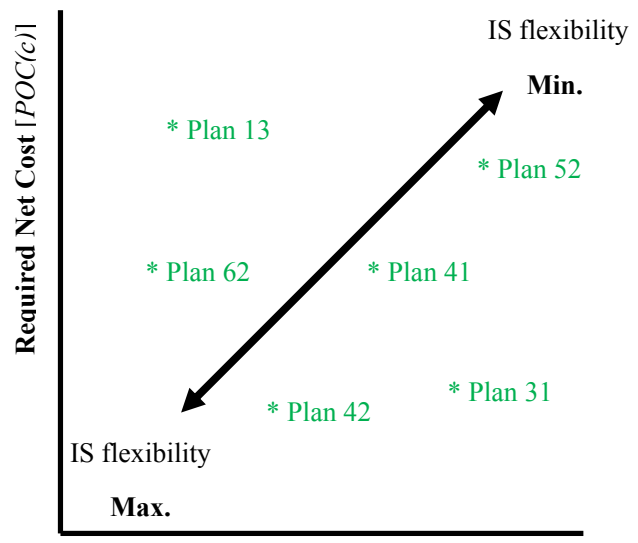

Required Net Time $[P O C(t)]$

Figure 4. IS Plans Mapped

To this effect, a caveat is in order. An observation in the literature exists to the effect that a high degree of urgency demanded on a project, which hardly allows enough time for appropriate requirement definition, will inevitably destabilize the structure of the project, and consequently, increase its risk vulnerability (Yin, 1981). This caveat suggests that when attempting to choose from among multiple-system alternatives, good care must be taken to shun ones with their lead time (the time factor of their POC) perilously reduced and choose ones that are optimally feasible.

\section{Conclusion}

On the basis of the analysis conducted in Part 1 of our study on our first question of "Why do information systems need to be flexible?" this paper addressed our second and more practical question of "How can we make information systems flexible?"

This paper began by defining IS flexibility in terms of our concept of $P O C$, and then suggested the renovation of the IS architecture to enhance IS flexibility and stressed the role that it plays in reducing the complexity of IS functions, thereby enhancing IS flexibility. We also defined the external and internal flexibility factors that underlie IS flexibility and analyzed their interrelationship. We devoted the latter part of this paper to proposing our notion of a supposedly appropriate manner in which we should construct a flexibility-oriented medium-term development plan, comprising an optimal combination of an IS architectural renovation and a series of IS modification projects.

The schema of IS development planning that we constructed, although rather crude, might provide a guiding principle for constructing an IS that can be relied upon to absorb incessant change demands with minimum POC. Further research is required of us on, e.g., "how to predict potential change demands and advances in innovative technology," "how to optimize the timeframe for a medium-term development plan," and "how to optimize the 
coverage of an organization's IS, which is actually expanding beyond the corporate borders".

\section{References}

Allen, B. R., \& Boynton, A. C. (1991). Information architecture: in search of efficient flexibility. MIS quarterly, 15(4), 435-445. http://dx.doi.org/10.2307/249447

Alter, S., \& Ginzberg, M. (1978).Managing Uncertainty in MIS Implementation, Sloan Management Review, 20(1), 23-31.

Anderson, D. J. (2004). The four roles of agile management. Cutter It Journal, 17(7), 11-17.

Beck, K., \& Andres, C. (2004). Extreme Programming Explained: Embrace Change (2nd ed.). Boston: Addison-Wesley Professional.

Bieberstein, N. S., Bose, M., Fiammante, J. K., \& Shah, R. (2006). Service-Oriented Architecture Compass. Upper Saddle River, NJ: Pearson.

Brooks, F. P. (1974). The Mythical Man Month. Datamation, 20(12), 44-52.

Browne, J., Rathmili, K., Sethi, S. P., \& Stecke, K. E. (1984). Classification of Flexible Manufacturing Systems. The FMS Magazine, IFS Ltd.114-117.

Byrd, T. A., \& Turner, D. E. (2000). Measuring the Flexibility of Information Technology Infrastructure: Exploratory Analysis of a Construct. Journal of Management Information Systems, 17(1), 167-208.

Ceryan, O., \& Koren, Y. Y. (2009). Manufacturing capacity planning strategies. CIRP Annals Manufacturing Technology, 58(1), 403-406. http://dx.doi.org/10.1016/j.cirp.2009.03.034

Chryssolouris, G., \& Lee, M. (1992). An Assessment of Flexibility in Manufacturing Systems. Manufacturing Review, 5(2), 105-116.

Chryssolouris, G. (1996). Flexibility and Its Measurement. Annals of the CIRP, 45(2), 581-587. http://dx.doi.org/10.1016/S0007-8506(07)60512-5

DeLone, W. H., \& McLean, E. R. (1992). Information System Success: The Quest for the Dependent Variable. Information Systems Research, 13(1), 60-95. http://dx.doi.org/10.1287/isre.3.1.60

Duncan, N. B. (1995). Capturing Flexibility of Information Technology Infrastructure: A Study of Resource Characteristics and Their Measure. Journal of Management Information Systems, 12(2), 37-57.

Economist. (2004). Make It Simple: A Survey of Information Technology (October 30).

Fink, L., \& Neumann, S. (2009). Exploring the Perceived Business Value of the Flexibility Enabled by Information Technology Infrastructure. Information and Management, 46(2), 90-99. http://dx.doi.org/10.1016/j.im.2008.11.007

Furukawa, M. (2000). Evaluating IS Effectiveness by Means of the Measure of Flexibility. The proceedings of the Fourth Pacific Asia Conference on Information Systems. Hong Kong.

Furukawa, M. (2001). Database Agile Management Dependent on MIS Infrastructure. Conference Proceedings of Informing Science 2001, Krakow, Poland, 198-213.

Furukawa, M. (2002). Conceptual Model for MIS Flexibility Evaluation. Information Systems Evaluation Management, Grembergen, W. (Ed.), Idea Group Publishing, 146-166.

Furukawa, M., \& Minami, A. (2013). A Study on the "Flexibility" of Information Systems (Part 1): Why do they need to be flexible? International Journal of Business and Management, 8(20), (unpublished).

Gebauer, J., \& Schober, F. (2006). Information System Flexibility and the Cost Efficiency of Business Processes. Journal of the Association for Information Systems, 7(3), 122-147.

Goldratt, E. M. (1997). Critical Chain. Wappingers Falls, NY: North River Pr.

Hirotaka, T. H., \& Nonaka, I. (1986). The New New Product Development Game. Harvard Business Review, 64(1), 137-146.

Horn, P. (2001). Autonomic Computing: IBM's Perspective on the State of Information Technology. White Paper, IBM T.J. Watson Research Center, Yorktown Heights, NY.

Hulet, L. (2004). Agile Development: Lessons learned from the first scrum. Development, 5, 1-4.

Laudon, K. C., \& Laudon, P. J. (2000). Management Information Systems (6th ed.). Organization and Technology in the Networked Enterprise, New Jersey: Prentice-Hall, Inc. 
Martin, J., \& Leben, J. (1989). Strategic Information Planning Methodologies (2nd ed.). Prentice Hall, Inc.

McFarlan, F. W. (1981). Portfolio Approach to Information Systems.Harvard Business Review, 59(5), 142-150.

Palanisamy, R., \& Sushil. (2003). Achieving Organizational Flexibility and Competitive Advantage through Information Systems. Journal of Information and Knowledge Management, 2(3), 261-277. http://dx.doi.org/10.1142/S0219649203000358

Parker, M. M., \& Benson, R. J. (1988). Information Economics: Linking Business Performance to Information Technology. New Jersey: Prentice Hall.

Plenert, G. J. (2011). Lean Management Principles for Information Technology (Resource Management). CRC Press.

Prahalad, C. K., \& Hamel, G. (1990). The Core Competence of the Corporation. Harvard Business Review (May-June). (Enhanced Edition, March 3, 2009).

Robey, D., \& Boudreau, M. C. (1999). Accounting for the Contradictory Organizational Consequences of Information Technology: Theoretical Directions and Methodological Implications. Information Systems Research, 10(2), 167-185. http://dx.doi.org/10.1287/isre.10.2.167

Robinson, W. N., \& Pawlowski, S. D. (1999). Managing Requirements Inconsistency with Development Goal Monitors. IEEE Transactions on Software Engineering, 25(6), 816-835. http://dx.doi.org/10.1109/32.824411

Rumbaugh, J., Blaha, M., Premerlani, W., Eddi, F., \& Lorensen, W. (1991). Object-Oriented Modeling and Design. Englewood Cliffs, New Jersey: Prentice-Hall.

Siau, K., Lim, E., \& Shen, Z. (2001). Mobile Commerce: Promises, Challenges, and Research Agenda.Journal of Database Management, 12(3), 4-14. http://dx.doi.org/10.4018/jdm.2001070101

Silver, M. S. (1991). Systems that Support Decision Makers: Description and Analysis. Chichester, UK: Wiley.

Soh, C., Sia, S. K., Boh, W. F., \& Tang, M. (2003). Misalignments in ERP Implementation: A Dialectic Perspective. International Journal of Human-Computer Interaction, 16(1), 81-100. http://dx.doi.org/10.1207/S15327590IJHC1601_6

Whiting, R. (2003). Money Machines. Information Week, 34- 44.

Wysocki, R. K. (2009). Effective Project Management: Traditional, Agile, Extreme. Hoboken, NJ: Wiley.

Yin, R. K. (1981). Life Histories of Innovations: How New Practices Become Routinized. Public Administration Review, 4l(1), 21-28. http://dx.doi.org/10.2307/975720

\section{Copyrights}

Copyright for this article is retained by the author(s), with first publication rights granted to the journal.

This is an open-access article distributed under the terms and conditions of the Creative Commons Attribution license (http://creativecommons.org/licenses/by/3.0/). 